\title{
NOVOS VENTOS, CARTÕES-POSTAIS FEIRAS DE SANTANA
}

\author{
Lucas da Silva Santos ${ }^{1}$; Elenise Cristina Pires de Andrade ${ }^{2}$ \\ 1. Bolsista PIBIC-AF/CNPq, Graduando em Licenciatura em Ciências Biológicas, Universidade Estadual de Feira de \\ Santana, e-mail: lucas_saj@hotmail.com \\ 2. Orientador, Departamento de Educação, Universidade Estadual de Feira de Santana, e-mail: nisebara@gmail.com
}

PALAVRAS-CHAVE: Fotografia; educação ambiental; filosofia da diferença

\section{INTRODUÇÃO}

Atrelado ao objetivo de interrogar a política de representação que percorre os encontros com imagens nos âmbitos diversos, propondo outras ressonâncias, atravessadas pela experimentação e pelos sentidos emitidos pelos signos, implicando em uma outra postura estético-política para a visualidade em todos os campos onde ela se faça presente e necessária.

Com isso busca-se poetizar os enquadramentos, experimentar desenquadrar os olhares, expressões da cidade em experimentação através das imagens, atentando a saída da política da representação, junto a conceitos e estudos da filosofia da diferença, potencializando a pluralidade do diálogo conectado com a perspectiva de educação ambiental e fotografia. A proposta fugir dos clichês fotográficos e do que é representado sobre a cidade, tendo como objetivo analisar as potencialidades políticas e poéticas da fotografia a partir da concepção deleuziana (1974) de tempo, com conceitos sobre duração, propondo uma (re)caracterização e (re)leitura dos espaços marginalizados de Feira de Santana, BA e junto a este cenário teóricoepistemológico, esta proposta configura-se de encontros com alunos do $7^{\circ}$ ano do Colégio Estadual Professor Maria José de Lima Silveira ${ }^{1}$ na intenção de trabalhar com cartões postais, analisando, discutindo e propondo novas criações com imagens e palavras e(m) educação ambiental

\section{MATERIAL E MÉTODOS OU METODOLOGIA}

Metodologicamente este trabalho foi desenvolvido em quatro etapas, onde no segundo semestre de 2016 realizamos os primeiros encontros para compor a primeira etapa, destinados a explicar o projeto, para a produção das primeiras observações dos estudantes bem como as sensações dos espaços vivenciados por eles. Essa apresentação consistiu em dizer dos objetivos do trabalho através de uma sequência de fotografias feitas por mim, sempre dos mesmos pontos, ordenadas pela data evidenciando um canteiro central da Avenida Getúlio Vargas, centro de Feira de Santana. Na segunda etapa, o trabalho contou com a câmera e os espaços vivenciados pelos alunos, onde a turma foi dividida em quatro grupos, com o intuito de que todos participassem na realização das fotografias e na seleção dos espaços a serem fotografados na praça do São José. Na terceira etapa da pesquisa a proposta foi discutir a questão dos espaços marginalizados, analisando o programa Google Earth ${ }^{2}$ a partir de print screens de imagens do centro da cidade, por fim a quarta etapa da pesquisa foi constituída

\footnotetext{
${ }^{1}$ Colégio situado no bairro do São José, distrito de Maria Quitéria, Feira de Santana, Bahia

${ }^{2}$ Aplicativo de mapas que permite ao usuário ter uma percepção virtual sobre qualquer lugar do planeta a partir do modo Street View (imagens capturadas por satélites). Fonte: <http://www.techtudo.com.br/tudo-sobre/googleearth.html>. Acesso em 04 de Agosto de 2017
} 
pela montagem dos cartões postais ${ }^{3}$, a partir de uma oficina de colagem, utilizando as fotografias produzidas na primeira parte do projeto.

\section{RESULTADOS}

Fotografias atravessadas por uma unidade de medida chamada tempo, desfocalizando os olhares para outras visualidades, de uma cidade despercebida no dia-a-dia. Junto a esse cenário teórico-epistemológico, os resultados aqui apresentados são resposta de encontros com alunos do $7^{\circ}$ ano. Encontros que ocorreram no segundo semestre de 2016, respectivamente nos dias 9 e 15 de agosto de 2016.

Relacionando as fotografias que foram produzidas com a questão mais teórica, as análises feitas se baseiam em alguns questionamentos: Que tempo se relaciona a essas imagens? Quais memórias atra-VERSAM esses novos cartões-postais? Com isso, a intenção é discutir a cidade e as fotografias, trazendo um diálogo sobre a exclusão dos espaços marginalizados, como também sobre o protagonismo apenas do centro da cidade no programa Google Earth. Assim, as fotografias produzidas têm a intenção de fazer com que a praça do São José se venha a ser um novo cartão-postal de Feira de Santana. Dessa forma os alunos são como artistas, pois com seu ato criativo, eles atra-VERSAM os clichês e o centro da cidade com uma representação da praça do São José, possibilitando-nos o ir ao encontro com as fotografias e o movimento de expressão que elas proporcionaram aos alunos, atuantes e (re)criativos.

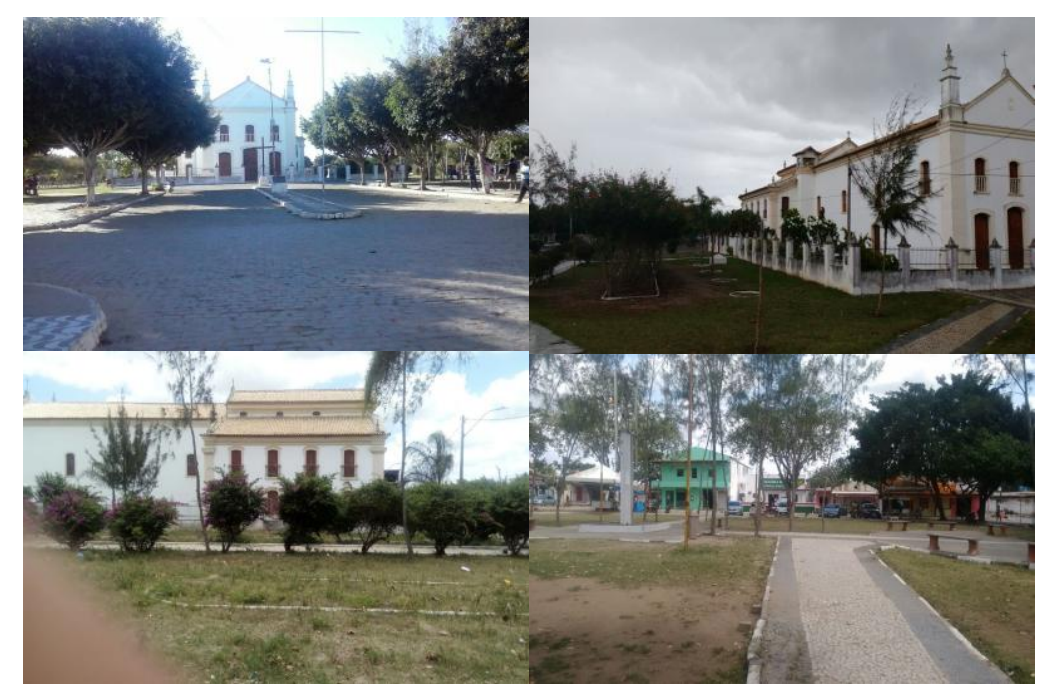

Figura 1: Fotografias realizadas pelos alunos na praça do São José.

As fotografias apresentadas estão movimentando o ato (re)criativo, com isso, as fotografias dos alunos se enquadra na categoria de enunciar uma nova expressão, tensionando e questionando os clichês fotográficos e, principalmente, sobre os cartões-postais estabelecidos, que remetem, quase que exclusivamente, ao centro da cidade.

Proponho uma análise da fotografia pautada em poetizar os olhares para experimentar desenquadrá-los, ou seja sair das expressões representacionais da cidade, buscando uma fuga

\footnotetext{
${ }^{3}$ A ideia de trabalhar com cartões postais tem como principal referência o projeto de pesquisa e extensão, desenvolvido pelo grupo "Humor Aquoso", da Faculdade de Educação e "MultiTÃO: prolifer-artes sub-vertendo ciências e educações", do Laboratório de Estudos Avançados em Jornalismo (Labjor), ambos da Universidade Estadual de Campinas (São Paulo, Brasil). A equipe é formada por professores, alunos e pesquisadores das áreas de educação, filosofia, artes e artistas visuais e fotógrafos convidados. Disponível em < https://fabulografias.wordpress.com/apresentacao/ > Acesso em 04 de Agosto de 2017.
} 
dessa política da representação, esses preceitos estão atrelados a questões sobre educação ambiental, onde a partir do momento em que os alunos experimentam realizar as fotografias e ao mesmo tempo mostrando uma outra praça do São José. Atuação (re)criativa que gera a "brincadeira" com a câmera, a fotografia em modo "paisagem" ou no modo "retrato". Ainda no movimento de desenquadrar essas fotografias possibilitam uma liberdade uma Feira desconhecida/esquecida, que nos atraem para um "gesto de criação" (WUNDER; ROMAGUERA, 2014).

Percebe-se que, com as fotografias, a praça se movimenta a todo instante, pode-se observar as nuvens que andarilham, as sombras, o dia nublado, a presença de algumas pessoas andando na praça, os estudantes conversando com a professora. Estes gestos presentes na fotografia propiciam a "criação" juntamente com o ato de vivenciar o ambiente. Vivência que possibilita que os alunos possam andarilhar no espaço criativo, como uma fuga dos clichês fotográficos. De um modo geral, podemos observar que as fotografias dos grupos são um terreno que pode ser semeado, na tentativa de (re)criar esse lugar marginalizado.

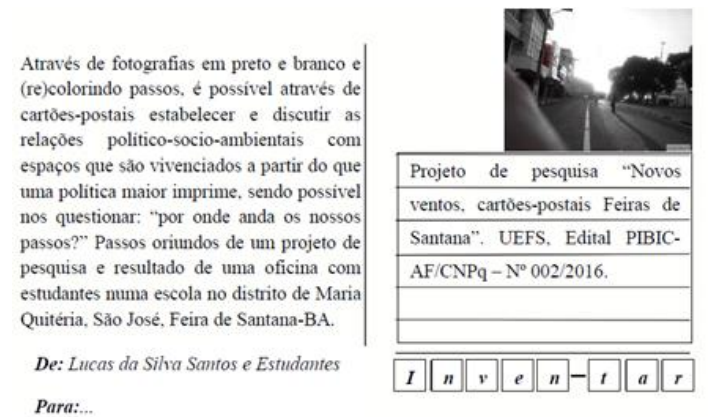

Figura 2: Cartão postal produzido para a oficina

de montagem e colagem das fotografias.

(Re)criação, vidas e cores ${ }^{4}$. Cartões que nos levam, a experimentar a fotografias através dos sentidos, desprendendo-as das representações, para dar expressão a novas visualidades, "potência de expressão para pensamentos acerca da educação e ambiente e questões ambientais" (ANDRADE; SPEGLICH, 2011, p. 124). Diante disso a ideia é dar espaço para uma nova (re)leitura, com a produção dos cartões postais pelos alunos, estes que tem uma conexão com os conceitos de Gilles Deleuze, principalmente sobre o tempo linear, o tempo cronológico, diante disso, interessa-nos:

A criação e o que se extrai desse fabular, interessam as potências e as possibilidades de vir a ser, sem a necessidade de efetuação. Deslocamo-nos, assim, de um tempo cronológico e suas amarras, das ideias de lembrança e de origem, deslocamentos que desejamos para nossos pensamentos (ANDRADE; SPEGLICH, 2011, p. 131).

Filho e Correia (2013), trazem ideias que estão no campo dos elementos como a afetividade, percepção, memória, experiências e ideias pré existentes no imaginário dos alunos, elementos que tem uma ligação com o ambiente e auxiliam no processo de (re)criação, gerando novas potencialidades imagéticas.

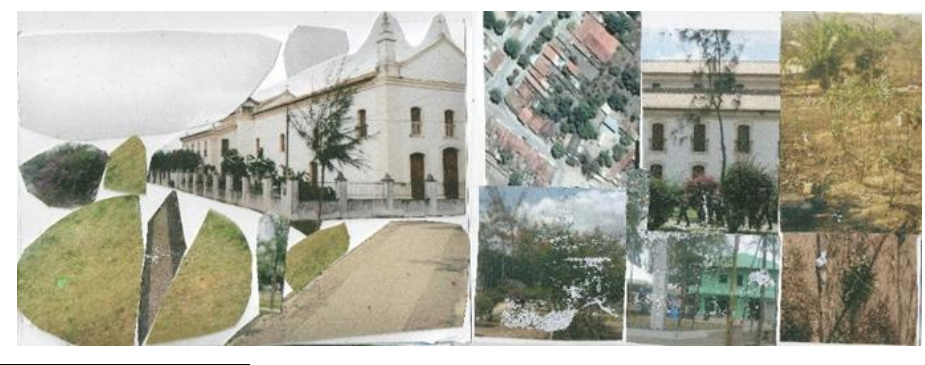

\footnotetext{
${ }^{4}$ Essa parte da pesquisa foi realizada entre Maio e Abril de 2017, com os alunos do $8^{\circ}$ ano, turma composta em sua maioria por alunos que participaram das etapas anteriores da pesquisa.
} 
Figura 2: Colagens produzidas pelos alunos na oficina de montagem

dos cartões postais.

Uma fissura para novas possibilidades de compreensão e de posicionamento acerca da realidade, essa é uma proposta que responde a vários questionamentos dessa pesquisa através dos postais produzidos, e principalmente o que versa o lado de investigar "entrelugares" marginalizados da cidade, que podem de certa forma serem pensados e expressos de outras formas, podendo quebrar a linearidade e certos preconceitos acerca de determinado local.

A/r/tografar passos, escadarias entre paralelepípedos e grama até janelas e ambientes (re)configurados. Temos borrões seguindo o trabalhador (talvez), que caminha, caminha... para varrer clichês. Os cartões postais são as construções subjetivas da margem e a estreita relação com o Google Earth como um "zoom”, que faz menção e aproximando do São José, com isso a praça começa a fazer parte ou se situar como uma referência, um novo cartão postal da cidade.

Um novo que se relaciona a essas imagens, atra-VERSANDO nesses cartões-postais, uma relação cidade-margem-fotografias, numa perspectiva que como foi proposto nessa pesquisa, que é o de discutir a cidade e as imagens, estabelecendo principalmente um diálogo sobre a exclusão dos espaços marginalizados e o porquê do protagonismo apenas do centro da cidade no programa Google Earth. Com isso é válido ressaltar, principalmente com os cartões mostrados anteriormente, que esse desafio proposto vem sendo superado, pois o ambiente começa a se inserir propositalmente nas entrelinhas do programa.

\section{CONSIDERAÇÕES FINAIS}

Com novos cartões postais Feiras de Santana, andarilhar por uma parte da cidade (des)conhecida permitiu ampliar os sentidos sobre o que é o marginalizado. Deixamos claro que ainda existem lugares da cidade a ser explorados e que também podem ser um novo cartão postal de Feira de Santana, o novo que foi e pode ser representado e evidenciado a partir do olhar de quem também é incluso na marginalização.

\section{REFERÊNCIAS}

ANDRADE, E.C.P de; SPEGLICH, É. 2011. Imagens a fabular ambientes: desejos, perambulações, fugas, convites. Pesquisa em Educação Ambiental, vol. 6, n. 1 pp. 123-137. DELEUZE, G. 1974. Lógica do Sentido; tradução de Luiz Roberto Salinas Fortes. São Paulo, Ed. da Universidade de São Paulo.

FILHO, A.V; CORREIA, M.B.F. 2013 Ponderações sobre aspectos metodológicos da investigação na cultura visual: seria possível metodologizar o enfrentamento elucidativo das imagens? In: Processos e práticas de pesquisa em cultura visual e educação) p. 49-60 ISBN 978857391 185-5.

WUNDER, A; ROMAGUERA, A. 2014. Experimentações coletivas por entre poesias, fotografias e ventos-áfricas. Informática na Educação (Online), v. 17, p. 31-45. 